\title{
Azares de amor y de guerra
}

Ivonne Saed*

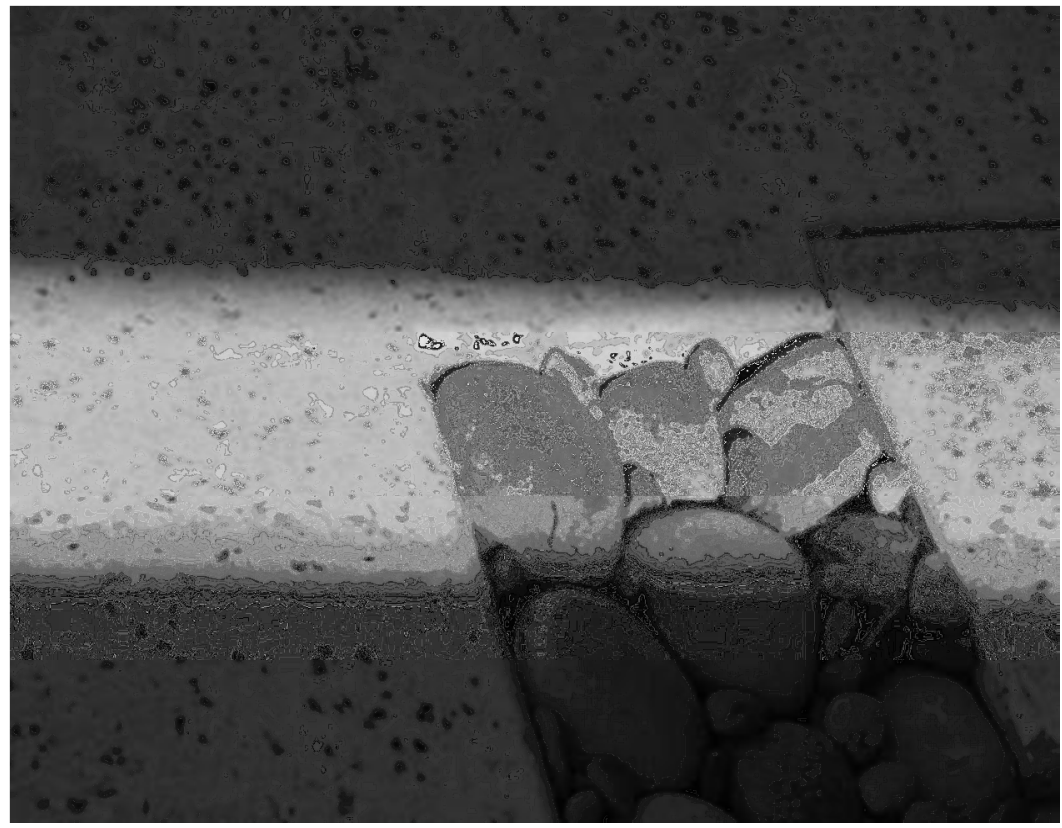

Rocas enmarcadas

(Framed Rocks)**

Fotografia digital $(\mathrm{p} \& \mathrm{~b})$

México, 2006

Si no hubiese sido por lo que pasó ese día, yo en principio ni siquiera estaría aquí. O mejor dicho no estaría en absoluto. No habría nacido, no se habría reunido nunca ese conjunto de factores - células, fluidos, manías, hábitos, olores, gustos, facciones y deseos - que como resultado dieron el universo irrepetible que es mi persona. Porque igual que para la guerra se necesitan dos, también para el amor y la procreación. Para el amor, al igual que para la guerra, además de dos participantes, se requiere también de un momento justo, una razón precisa, la reunión exacta de elementos que no pueden aplazarse ni suceder en un espacio distinto. Si cualquiera de las partes que forman un suceso bélico o amoroso aconteciera a un metro de donde sucedió o unos minutos después, sería como si el mundo hubiese cambiado su velocidad de giro por un momento imperceptible y a la vez irrecuperable: entonces nada sería igual.

Ese preciso y remoto día de enero en que mi abuela se levantó antes del amanecer a preparar la comida para recibir y agasajar a sus futuros consuegros por vez primera fue elegido por el azar para cambiar el curso de nuestras vidas; ese azaroso día significó de hecho la vida para muchos y la no existencia para otros. Así fue: si esa señora flaca, demacrada y sonriente no hubiera tocado la puerta de casa de mi abuela ese nublado y frío día de enero de mil novecientos cincuenta, ninguno de nosotros estaríamos aquí; otros estarían en nuestro lugar y quién sabe qué es lo que sería del mundo.

Eran las seis de la mañana. El cuarto aún estaba totalmente a oscuras. Ni un solo indicio del amanecer se asomaba a saludar a través de la rendija que quedaba siempre abierta entre las dos cortinas. Ese era el reloj matutino de mi abuela desde que vivían ahí. Las cortinas las había recibido como regalo de una prima que llegó a México un año antes de la guerra y como mejor era eso que nada, las había adaptado al tamaño de su ventana, descosiendo uno de cada tres pliegues para que dieran el ancho; esa rendija delgada que le daba la hora cada mañana era el recordatorio de su buena suerte y su pobreza simultáneas. Le recordaba su pobreza no sólo por no cubrir la ventana completa, sino porque esa rendija le servía efectivamente de reloj a falta de uno de verdad. Pero también la ponía en contacto

Arquivo Maaravi: Revista Digital de Estudos Judaicos da UFMG. Belo Horizonte, v. 1, n. 1, out. 2007. ISSN: 1982-3053. 
con su fortuna: toda esta pobreza era símbolo de vida, era el intercambio que habían tenido que negociar entre tener y ser, entre conservar una posición que a la larga también se acabaría perdiendo o continuar la vida en un recóndito país del que no sabían nada, empezando por el idioma, pasando por su geografía y terminando por sus costumbres.

Cuando mis abuelos maternos transaron entre sí y con su propia conciencia el intercambio, lo único que sabían de su futuro lugar de residencia era que se llamaba México y que para llegar a él habría que cruzar el mar. Pero sabían también otra cosa: que era su única alternativa para conservar la vida de ellos y de sus tres hijos - por un período más largo que algunos meses. Por eso no lo pensaron demasiado cuando tuvieron la oportunidad de abandonar la Francia ocupada con los pasaportes falsos que les habían costado la mitad de todo lo que tenían; por eso se precipitaron a tomarlos y a confiar las joyas de mi abuela a un mensajero clandestino que aparentemente se las entregaría a bordo del barco, ya a salvo de la inspección nazi, a cambio de una sustanciosa comisión que acabó siendo del cien por ciento; por eso eran felices aquí a pesar de no hablar bien el español, a pesar de que mi abuelo había tenido que caminar durante horas cada día para vender calcetines de puerta en puerta en lugar de trabajar sentado frente a su antiguo escritorio de caoba oscura dictando órdenes, a pesar de que por mucho tiempo tuvieron que comer más papas y arroz que carne y pescado. Aquí eran vistos como extraños, raros, forasteros, hasta un poco invasores quizá, pero siempre como humanos.

Desde el primer día que despertaron en México y hasta muchos años después, mi abuela tuvo la costumbre de levantarse al aparecer sobre el piso la tajada de luz que anunciaba el amanecer y que dividía en triángulos perfectos e idénticos cada una de las baldosas por las que atravesaba. Esa mañana de invierno, en cambio, se había adelantado al anuncio solar. Los nervios, la incertidumbre y la agobiante y ardua actividad que le esperaba ese día la empujaron fuera de la cama una hora antes de lo acostumbrado. Como siempre, lo primero que hizo fue orinar, se lavó después la cara y los dientes y se fue a la cocina a continuar los preparativos de la gran cena que serviría esa noche a sus futuros consuegros. Su situación económica había mejorado un poco desde su arribo a México y ya tenían algo de dinero ahorrado para regalar a sus hijos en el momento en que decidieran casarse y comenzar su propia vida. Había llegado el momento.

Mientras con una mano amasaba la mezcla de pescado, azúcar y condimentos para ablandarla y hacer las bolitas, con la otra se comía lentamente una manzana amarilla. Una hora después el guefiltefish estaba listo y ahora quemaba la piel de los pollos en la lumbre para preparar el plato principal. En eso estaba cuando mi abuelo entró a la cocina, repelando por el horrible olor a esa hora de la madrugada. Mi abuela dejó los pollos un rato, exprimió un par de naranjas, tostó pan y se sentaron juntos a desayunar sus huevos tibios de cada mañana y a hacer el recuento obligatorio del transcurso de los años que se hace en este tipo de ocasiones.

- Quién hubiera dicho que acabarías en México desplumando pollos para el compromiso de Tamara. Apenas un poco más de diez años hace que creíamos que seguiríamos siendo alemanes, millonarios, orgullosos y felices por el resto de nuestros días.

Mi abuela contestó con un cronch de su pan tostado y un brillito de múltiple significado en los ojos.

- Todavía en Estrasburgo yo tenía la esperanza de que todo ese horror sería un mal sueño que se iba a acabar muy pronto, que regresaríamos a nuestra casa en Berlín y nos pedirían perdón por los inconvenientes... Quién sabe que habrá sido de la casa. Ojalá se haya caído de un bombazo. No soporto la idea de que ahí vive un nazi mugroso que se pone mi pijama. 
- Si no soportas la idea, no sé para que la invocas. Además, en vez de estar haciendo recuento de desgracias, deberías de ayudarme con los pollos porque si no, vamos a tener que cancelar la cena a falta de comida hasta nuevo aviso.

A veces uno dice cosas como para hacerse el simpático, para cambiar el tema o nada más porque sí; o porque las palabras las manda el azar caprichoso que se empeña en demostrarnos que tiene más poder en nuestras vidas de lo que somos capaces de aceptar o entender. En este caso era una mezcla de todo a la vez: mi abuela quería ser simpática porque el día lo ameritaba y quería cambiar el tema porque simplemente no podía tolerarlo: le dolía demasiado. Para ella el saldo de la guerra no sólo había sido muy alto sino además, incierto. Todavía ese azaroso día de mil novecientos cincuenta ella seguía sin saber nada de su única hermana. A sus padres los habían matado en Auschwitz y a su hermano le dispararon muy al principio de la guerra al tratar de cruzar la alambrada del gueto. Eso lo sabía con certeza. Pero de su hermana hasta hoy no sabía nada, ni siquiera a dónde la llevaron.

Cuando mi abuela terminó de pronunciar esa frase, mi abuelo ya la estaba ayudando a quemar los pollos y todo indicaba que la cena que al final se canceló, se llevaría a cabo con toda la alegría y puntualidad que suponía la ocasión.

Tamara - mi mamá - era la única mujer de tres hermanos y era la mayor. A sus veinte años, tenía más experiencia en cocina y trabajo rudo que cualquiera de las niñas o niños con los que había estudiado la primaria. Hablaba español casi sin acento y sólo cuando se emocionaba mucho se le salía una erre afrancesada y gutural que no dejaba muy claro su origen étnico de cualquier forma, porque le daba a las sílabas una declinación extraña que hacía extraviarse hasta al más suspicaz de los lingüistas. A su novio lo había conocido en la sinagoga muy poco tiempo después de haber llegado a México y era su único vínculo real con el país; la única persona que le ayudaba a contrarrestar la nostalgia de su vida anterior. Esta circunstancia hacía dudar un poco a mi abuelo respecto a la autenticidad del amor de su hija por Isaac. Para él era una cuestión de apego más que de amor, pero no se animaba a manifestarlo frente a su hija o su esposa. Después de todo, mi madre ya no era una niña como para inmiscuirse de esa manera en sus decisiones e Isaac era una buena persona. Por su parte mi abuela también tenía ese temor muy en el fondo pero tampoco lo manifestó sino hasta muchos años después, cuando yo ya era un niño sin pañal y con uso de razón.

A eso de las diez de la mañana, mientras mi mamá se pintaba las uñas y el olor a pollo quemado se adueñaba de la casa entera, tocaron a la puerta. Tamara corrió a abrir. Estaba mucho más ansiosa que contenta y cualquier cosa irregular la ponía tensa desde el principio de la semana. No sonreía cuando abrió la puerta ni después de ver a la mujer que sí le sonrió a través del umbral. Mi abuela asomó la cabeza desde la cocina. El rostro que vio le dijo algo sin palabras que le revolvió el estómago, mientras la extraña la saludaba por su nombre en yidish. La mujer se presentó como Guite Yanovsky y su sonrisa triste era como de la familia. Mis tíos y mi abuelo ya no estaban en la casa a esa hora y las dos mujeres ofrecieron algo de tomar a la recién llegada mientras ella se sentaba frente a la mesa llena de comida a medio preparar. A la conversación trivial acerca del compromiso de mi madre y la comida de la noche, siguió un abismo de silencio que exigía explicación. Era como un tren que no alcanza a tocar tierra firme mientras el puente debajo comienza a crujir con su silencio flotante. Guite sacó de su bolsa un paquete chiquito, que cabía en el puño de su mano. Era un envoltorio de franela que desenrolló sobre un costado de la mesa. La explicación que vino entonces ya no era necesaria para mi abuela, pero era indispensable para mi mamá que sólo sentía una aguja cruzándole el abdomen sin entender porqué. 
- Tu hermana Frida fue como mi hermana en el campo de concentración. Desde la primera noche que pasamos juntas en el tren, supe que no me separaría de ella jamás. Siempre hablaba de ti, de su hermana mayor y admirada, de sus sobrinos queridos. Decía que cuando se acabara la guerra ella se iba a casar y a tener unos hijos iguales a los tuyos, que iban a ser vecinas y a compartir el jardín para que sus hijos pudieran jugar mientras los tuyos los cuidaban. Siempre hablaba de planes inmediatos, como si la guerra no se estuviera bebiendo nuestras almas, como si a la vuelta de la esquina estuviera la salida del pozo de pesadillas reales en que todos estábamos latiendo sin vida. Llegando al campo nos bajaron del tren y nos empujaron dentro de un espacio mínimo donde sería nuestra casa. Nos obligaron a desnudarnos mientras nos rociaban con un líquido que apestaba. Frida hacía bromas de lo que pensaría su novio del asqueroso olor. Un día entraron unos oficiales de más alto rango y señalaron a algunas de nosotras. Eran las más jóvenes o las más guapas. Entre ellas estaba tu hermana. Desde ese día su trabajo era privilegiado. Comían bien y pasaban algunas noches con nosotras y otras noches con algún oficial. No podían negarse. Nadie podía negarse a la voluntad de los nazis. Frida se convirtió en la favorita de uno de los oficiales y se mudó a vivir con él. Tenía un cuerpo precioso y era muy guapa, pero siempre iba por el campo con la mirada perdida. Solamente a veces, cuando podíamos hablar un momento, empezaba a hablar de ti y de tu familia, de su novio y de sus planes. Entonces le brillaba la mirada. Unas semanas antes de la liberación algo pasó entre ella y el oficial que lo hizo enfurecerse. Nunca supimos qué fue. La mandaron de nuevo con las demás y le preguntamos lo que había acontecido pero ella nunca nos dijo. Esa noche nos acostamos juntas y nos quedamos abrazadas sin dormir muchas horas. En la madrugada se quitó esta cadena del cuello con esta mano de oro y me la dio. Me contó que tú se la habías regalado para que la protegiera. Me pidió que si yo sobrevivía, te buscara y te la diera de regreso. Ya sabía que la iban a matar. Esa mañana se llevaron a la mitad de las mujeres de nuestra barraca a la cámara de gas.

Vino otro puente de silencio sin rasgaduras. Después de varios minutos que en su pasar reflexivo cambiaron el destino de las tres mujeres, mi mamá se quedó viendo sus uñas todavía frescas por apenas un poco más de un instante y las embarró en el mantel. Apenas se alcanzó a oír su voz gutural:

- Para qué. No tiene ningún caso - y salió de la casa.

Mi abuela se levantó de la silla después de un rato y abrazó a Guite. Le puso la cadena alrededor del cuello, mientras la escuchaba decir:

- Me tomó mucho tiempo encontrarte. Lo único que sabía de ti es que vivías en México y nada más. Yo me fui a Nueva York con mi tío terminando la guerra pero no teníamos dinero para viajar. Yo sabía que solamente viniendo aquí te iba a poder encontrar. Ya ves: tuve razón.

Todavía se quedaron sentadas un buen rato sin hablar. De vez en cuando se acariciaban las manos hasta que Guite rompió el silencio para despedirse, mientras escribía algo en un papel. Ya no tenía mucho más qué hacer ahí.

- Nos veremos otra vez algún día - y le extendió a mi abuela el papel con su dirección.

- En la boda de Tamara - contestó mi abuela sin sonreír.

- Pues ya veo que es muy próxima, no creo vaya a regresar tan pronto de Nueva York.

- Quizás no sea tan próxima como parece. Y claro que vas a estar aquí. La familia es la familia Contestó mi abuela otra vez sin sonreír. 
Mientras tanto, Tamara ya caminaba sin destino por las calles del centro. Sentimientos de confusión y alivio competían por dirigir sus pasos. Recordaba lo que una vez Isaac le había dicho como si fuera el mejor chiste: “¿Quieres hacer reír a Dios? Cuéntale tus planes"... Era tan cierto y tan poco gracioso que ahora que lo pensaba no podía más que llorar. El vínculo con Isaac había compensado durante toda su adolescencia la incertidumbre de que algo aún quedaba en Europa por lo que ella tendría que regresar algún día. Era como saber que un imán gigante podía hacerla regresar involuntariamente. Aunque su madre no hablaba casi nunca de Frida, mi mamá sabía que de estar todavía viva, ella estaba expuesta a que el gran imán la atrajera a la Europa a la que no quería jamás regresar. Isaac había representado siempre el lazo que la detenía aquí, el único contrapeso que podía resistir la fatal acción que la atraía a su tenebroso origen para buscar las piezas faltantes del engranaje de su existencia familiar.

Ahora la pieza se había perdido para siempre y tocaba llenar el hueco con una pieza coherente que en este caso no era Isaac sino el duelo. Él podía ser el mejor hombre sobre la tierra y el más querido, pero nunca encajaría en el hueco que sólo podía taparse con el tiempo, con las lágrimas que hay que llorar y los recuerdos que hay que evocar para despedirse de los muertos. Se daba cuenta y le entristecía saber que ahora Isaac ya salía sobrando. Su función en la vida de mi madre había llegado a su fin. Lo quería profundamente pero no lo amaba. Fue su ancla en puerto seguro, pero nunca la enseñó a volar; era su contacto con la realidad inmediata, pero nunca pudo inspirarla para soñar. El corazón de marino de mi madre estaba liberado de la atracción del canto de las sirenas y ya no podía permitirse naufragar. Por primera vez se encontraba con su ser irremediablemente libre; los lazos que contrarrestaban la acción magnética se habían roto en un efecto de resorte. Ella quedaba de este lado del mundo sola, libre, Tamara.

Era ya la tercera vez en el día que pasaba por el Zócalo. Llevaba horas caminando. En la reja de entrada de la catedral se detuvo a comprar unos tubitos de pinole. Un hombre alto, casi sin pelo y ojos azules, se acercó y le preguntó con inconfundible acento alemán:

- What is that? Is it sweet?

- It's very sweet - y continuó en alemán - se llama "pinole". En tu país no hay nada igual que pueda ser tan dulce y delicioso. Deberías probarlo... o hasta exportarlo a Alemania. Sería un gran negocio. Sólo acuérdate de no chiflar mientras lo comes.

La vendedora de pinole, que no entendía nada, estiró la mano con curiosidad para recibir el dinero que unos dedos de uñas sumamente descuidadas le entregaban.

Cuando mi abuelo y mis tíos regresaron de trabajar esa tarde dos horas más temprano que siempre para ayudar a mi abuela con lo que faltaba para la fiesta, se encontraron con una casa que parecía recién bombardeada. Toda la comida a medio preparar seguía exactamente en el mismo lugar que estaba cuando salieron en la mañana y en las mismas condiciones. Mi mamá no estaba en la casa y mi abuela estaba sentada con los ojos llorosos y enrojecidos frente a la mesa del comedor.

- Pero ¿qué diablos está pasando aquí? ¿Qué tienes? ¿Estás enferma? ¿Dónde está Tamara? Los consuegros llegan en dos horas - atropellaba las palabras en yidish revuelto con español.

- Pues háblales a avisar que no vengan.

- ¿Me puedes explicar qué está pasando? No entiendo nada. 
- Mi hija no se compromete hoy. Se cancela todo.

- ¿Ah, sí? ¿Y me puedes explicar por qué?

- Porque es de mala suerte.

- No me vengas con estupideces - verdaderamente lo estaba sacando de quicio. ¿Y se puede saber por qué es de mala suerte?

- Porque finalmente ahora sí estoy de luto.

En ese momento entró Tamara a la casa.

- Se cancela mi boda.

- A ver si tú me explicas porque no entiendo nada.

- Ya hablé con Isaac. No entendió aunque trató - dijo Tamara sin tomar demasiado en cuenta lo que mi abuelo le preguntaba; más bien hablaba con su madre. Trató mucho de convencerme. Sus papás ya saben también todo. Él les avisó. Ya no tienes que hablar para cancelar.

- ¿Pero qué pasó, con un demonio? - volvió mi abuelo a combinar las lenguas, mientras mis tíos no decían ni hacían nada.

Mi madre se metió a su cuarto sin contestar. Sus hermanos la siguieron. Ya sola con su esposo, mi abuela le explicó todo lo que había pasado esa mañana. De cómo llegó esa mujer que sonreía todo el tiempo por el solo hecho de estar viva; de la historia de Frida, del oficial nazi empecinado, de la mano de oro, de las hermanas mutuamente autoadoptadas, de los sueños de Frida, sus planes, su deseo de ser feliz con su hombre; de cómo Tamara restregó las uñas en el mantel y renunció a su novio de consolación al que no amaba; de cómo su hija, en unos minutos, se transformó de niña a mujer de verdad; le contó de su mirada sin alegría, de la inercia rota, del resucitar la energía de Frida en la decisión de Tamara. Mi abuelo fingía seguir sin entender, aunque en realidad comprendía muy bien lo que estaba pasando y secretamente se alegraba.

Mi abuela se rasgó las ropas y llevó el duelo con todo su ritual durante una semana. Más o menos un mes después, mis padres se conocieron en una fiesta en casa de la prima que les había regalado las cortinas a mis abuelos. Él era socio del esposo de la prima en una pequeña fábrica de calcetines de algodón. Tenía veinticinco años, ojos verdes y muy buen humor. Al segundo chiste que le contó a mi mamá, ella ya estaba totalmente enamorada. Bueno, eso es lo que él dice. Ella dice que no es cierto. Lo que es cierto es que se casaron dos semanas después y que Guite Yanovsky estuvo en la boda porque todavía no se regresaba a Nueva York. También es cierto que yo existo como resultado del azar de un encuentro casual que pudo ser efímero y no fue; que estuve muy cerca de no haber nacido; que nací en México y no en Francia ni Alemania ni Nueva York. Es cierto que aquí y en este presente en que escribo estoy enamorado de la mujer que quiero que sea madre de mis hijos: esos seres que están en nuestra imaginación aunque todavía no existen y que le darán al universo su propio giro único e irrepetible; que se mezclarán y reunirán nuestras células, fluidos, manías, hábitos, facciones, deseos, gustos y olores con los caprichos del azar y entonces iremos descubriendo juntos, una a una, las sorpresas que nos depara el destino. 
*Ivonne Saed é escritora, fotógrafa e artista gráfica. Em 2003 publicou o romance Triple crónica de un nombre. Atualmente é coordenadora do projeto EntreSujetos, no México.

**C Copyright Ivonne Saed. 2006 